\title{
Clinical gait and stepping performance measures in older adults
}

\author{
N. B. Alexander • A. Goldberg
}

Published online: 22 March 2006

(C) EGREPA 2006

\begin{abstract}
Problems with ambulation and mobility are frequent problems in older adults. Each year, about one in 100 older adults develops new severe mobility disability. Assessment of abnormal gait constitutes a major component of clinical practice and may lead to fall reduction. Clinicians can benefit from simple gait and mobility assessment tools to be used in busy clinical settings. This review focuses on gait and stepping performance measures that can be used by the busy clinician to assess gait, mobility performance, balance, and falls risk in the older adult.
\end{abstract}

Keywords Gait disorders · Aging ·

Functional assessment

\section{Introduction}

Difficulty ambulating and problems with general mobility are frequent complaints of older adults. Each

\footnotetext{
N. B. Alexander Geriatric Research Education and Clinical Center,

Ann Arbor, MI 48109, USA

A. Goldberg

Department of Health Care Sciences,

Program in Physical Therapy,

Wayne State University,

Detroit, MI 48201, USA

N. B. Alexander $(\bowtie)$

Geriatrics Center, CCGCB Room 1111,

1500 East Medical Center Drive,

Ann Arbor, MI 48109-0926, USA

e-mail: nalexand@umich.edu
}

Mobility Research Center, Division of Geriatric Medicine, Department of Internal Medicine, Institute of Gerontology, University of Michigan, VA Ann Arbor Health Care System, year, about one in every 100 older adults develops new severe mobility disability, defined as the inability to walk across a small room or the need for help from another person to do so [20]. Assessments and interventions to improve gait are commonly used in older adults. Although management of abnormal gait constitutes a major component of physical therapy practice, a recent survey of clinical physiotherapists noted that there was no systematic use of standardized gait assessment tools, and that less than one-quarter utilized a gait laboratory for assessment [72]. The vast majority of these therapists requested a gait assessment tool, a simple clinical measure that could be used easily and quickly within a busy schedule without compromising reliability and validity. We review various gait assessment tools, including a performance-based set of multiple tasks, and stepping tasks. Outcomes are simple and, at most, require measures of distance, timing, or counting.

\section{Performance-based measures}

High-tech assessments that involve formal kinematic and kinetic analyses have not been applied widely in clinical assessments of older adult balance and gait disorders. Instead, a set of functional gait and balance tasks (which includes gait-related tasks such as turning while standing) has been proposed as a means to detect and quantify abnormalities and direct interventions. These tasks are either timed or scored semiquantitatively, usually based upon whether a subject is able to perform the task and if able, how normal or abnormal the performance was. Compared to more sophisticated high-tech assessments, these sets of tasks 
are easy to perform by virtually all levels of appropriately trained personnel and require virtually no equipment or testing time, and generally are valid. These sets of tasks provide a specific functional evaluation that is relevant to walking and may give clues to deficits in specific areas that are critical to level of dependency and that are amenable to physical therapy. A major issue is whether the simple measures are reliable and stable, particularly in diseased populations with potentially unstable clinical status. These scales are noted to be reliable in smaller, selected published samples but perhaps less reliable in larger epidemiologic settings (e.g., see [54] for critique of timed up and go test). Furthermore, as with any timed test, increased performance time may indicate more impairment or disability but may be the desired adaptation to maintain safety, particularly in someone at risk for falls. As far as the patient may be concerned, completion of the task, albeit slowly, safely, and without undue exhaustion, may still be preferable to being unable to perform the task at all.

\section{Gait speed}

Gait speed has become a powerful assessment and outcome measure. Gait speed measured as part of a timed short-distance (e.g., 8 feet) walk or as measured in terms of distance walked over time (such as $6 \mathrm{~min}$ ) predicts disease activity (such as in arthritis), cardiac and pulmonary function (particularly in congestive heart failure), and ultimately mobilityand activities of daily living (ADL) disability, institutionalization, and mortality. Gait speed is affected by a number of factors, including disease (such as cardiopulmonary), leg function (such as strength), and other factors such as falls and physical activity. For a full review, see [1].

Usual and maximal gait speed. Over relatively short distances (e.g., $5 \mathrm{~m}$ ), usual walking speed may predict subsequent functional dependence for the old-old (aged 75 and over), while maximal walking speed appears to be most sensitive in predicting functional dependence for adults aged 65-74 years, with functional dependence being defined as a new disability in one or more of the five basic activities of daily living, or death [61]. However, maximal-walking speed (walking as fast as possible such as on a 30 -foot walk which includes one turn), is one of the factors which can independently predict cognitive decline prospectively in healthy older adults [41]. In a recent study, Studenski [67], in studying the impact of gait speed on functional outcomes, excluded the extremely fit (gait speed $>1.3 \mathrm{~m} / \mathrm{s}$ ) and the very impaired $(<0.2 \mathrm{~m} / \mathrm{s}$ ) and identified values of $<0.6$ and $>1.0 \mathrm{~m} / \mathrm{s}$ as slow and fast walking status, respectively. These latter speeds are useful in predicting hospitalization and functional decline. Of note, while test-retest comparison of gait speed between clinic and a home visit 1 week later was good ( $\mathrm{ICC}=0.84)$, there is a suggestion that some of the slow walkers walked more quickly in the clinic [67]. Overall, gait speed test-retest reliability (intraclass coefficients, ICC) tends to be high for short periods, such as in: Parkinson's disease, for usual gait speed and stride length, 1-week test-retest ICC's $>0.9$ [73]; knee osteoarthritis, for usual and fast walk speed, 1-week test-retest ICC's generally $>0.9$ [16]; stroke patients measured at home 1 year poststroke, for usual 10meter walk speed for 1 week ICC $=0.97$ [17]; and mildly functionally impaired older adults, usual walk speed, 2-week test retest $\mathrm{ICC}=0.79$ [28]. In a large epidemiological sample tested 2 to 3 weeks apart, the testretest ICC for usual gait speed is lower (0.72) [50]. Comfortable gait speed over a 5-meter distance, as compared to timed up and go test (see below) or fast walk speed, is thought to be most responsive to change (i.e., to detect clinically relevant change) after 1 month of stroke rehabilitation [58]. Differences in walking speed may relate to whether average speed is determined from gait initiation, or if the speed is determined while the subject is already at constant velocity. Six-minute walk test. Self-paced 6-min walking distance is particularly useful in patients with cardiopulmonary disease [22]. For example, the six-minute walk test (SMWT) discriminates between New York Heart Association levels of congestive heart failure, and predicts hospitalization rates and mortality attributable to congestive heart failure [9]. The SMWT correlates with age and self-reported physical functioning as well as performance on a number of other balance, gait speed over short distance, and leg strength measures in mildly mobility-impaired older adults [4, 24, 35]. When applied in a rehabilitation setting, the SMWT is also sensitive to changes occurring during posttotal knee arthroplasty [51] and as a result of an exercise program to improve function in knee osteoarthritics [14]. Reliability is excellent: 1-week test-retest Pearson's $r=0.95$ in community-dwelling older adults of varying function [24], ICC $=0.94$ in peripheral vascular disease patients [48], and $\mathrm{ICC}=0.93$ in mobility impaired patients [30]. A number of studies have noted small improvements in consecutive testretest distances, e.g., approximately $6 \%$ in patients undergoing cardiac rehabilitation [23]. An important concern with the SMWT is the motivation to perform 
maximally, i.e., some subjects will "pace" themselves to be able to complete the test instead of trying to cover as much distance as possible. Given the relatively good relationships between SMWT and self-assessment of functional limitations [e.g., 23], this "pacing" may thus reflect what the subject feels that he/she is able to perform on a daily basis (i.e., usual behavior) rather than their capacity. While designed to be a test of exercise endurance, in some patients with heart failure, the peak oxygen uptake during SMWT may approach peak values attained by standard treadmill testing, i.e., the test may also be considered a test of peak performance [15]. Peak oxygen uptake during SMWT may approach $80 \%$ of the peak oxygen uptake during treadmill testing [29], suggesting that the SMWT is a near maximal exercise even for some healthy older adults.

Long distance corridor walk (LDCW). The LDCW allows measurement of walking speed of more than 20 $\mathrm{m}$, the distance covered in $2 \mathrm{~min}$ and the time taken to walk $400 \mathrm{~m}$. The 2-min walk serves as a warm-up for any practice effects and the subsequent $400 \mathrm{~m}$ portion gives a goal of distance, rather than time, and thus helps to better maintain a higher speed instead of "settling in" to a comfortable pace [65]. The LDCW has been used among relatively high functioning older adults (without apparent walking difficulty or disability) as a measure of health status and fitness, in that performance correlates with measures of clinical and subclinical disease, heart rate and blood pressure response, and physical activity [49]. The LDCW can help further delineate functional performance decrement, i.e., $26 \%$ of these high functioning older adults did not complete the full test: (1) because of cardiacrelated abnormalities, $13 \%$ were excluded from participation; (2) of those eligible, $2 \%$, could not complete the 20 -min walk, $2 \%$ did not begin the 400 -meter walk, and $9 \%$ could not complete the full distance, making another $13 \%$ of those eligible who could not complete the full test $[49,66]$. This leads to an important concern regarding how to provide a meaningful score in lower functioning older adults, many of whom cannot complete the full 400-meter walk. For example, the mean SMWT distance in mildly mobility-impaired community older adults in one study is $448 \mathrm{~m}$ [4] and $374 \mathrm{~m}$ in congestive heart failure patients, with over $50 \%$ of those Class II and over $75 \%$ of those Class IIIIV unable to walk more than $375 \mathrm{~m}$ [9]. In a more recent study, nearly one third $(32 \%)$ of participants were unable to complete the 400-meter walk, and although test-retest distances were nearly identical, no reliability coefficient was reported in regards to distance [55].

\section{Sets of multiple tasks}

The gait assessments described below are among the most common found in the literature. For the sake of brevity, other important assessment batteries that focus on postural control under various conditions, but that have limited gait-related items, such as the Berg balance scale $[6,7]$ are not included.

Dynamic gait index. The dynamic gait index (DGI) was developed to evaluate gait alterations in response to changing task demands, including changing gait speed, head turns, turning, clearing an obstacle, and stair climbing. Interrater and test-retest reliability has been reported as $>0.96$ (after rater training), and as with a number of scales [including the performanceoriented mobility assessment (POMA), see below], the DGI was responsive to change with exercise [64]. The DGI also has utility in discriminating between people with and without balance disorders [80]. In people 60 years and older, the DGI correctly identified $83 \%$ of people as belonging to either a balance disorder or control group [80]. In community-dwelling samples, using a cut-off score of 19 or less, sensitivity and specificity were fair in predicting falls: 59 and $64 \%$, respectively [62], and 85 and $38 \%$ in older adults with dizziness [79]. Subsequent interrater reliability was variable in individual items (kappa 0.35-1.0), and good for total score (kappa 0.64, Spearman $r=0.95$ ) in a vestibular-impaired sample of varying age and with a possible ceiling effect in the total score [84]. A shortened version of the DGI with three new items thought to be particularly challenging to vestibular patients (walking backwards, with eyes closed, or on a narrowed support) has recently been reported [83].

Emory functional ambulation profile. The Emory functional ambulation profile (EFAP) measures the time to walk under five environmental circumstances, with and without the use of an assistive device in stroke patients: (1) 5-meter walk on hard floor; (2) 5-meter walk on short pile carpeted floor; (3) timed up and go (as below); (4) step over a brick and then around a trash can; and (5) walk up four steps, turn around, and return (using hand rail if needed) [81]. A modified version (mEFAP) incorporated manual assistance (contact guard, minimal assist, and moderate assist) in stroke patients undergoing day rehabilitation [3]. In these small samples, both EFAP and mEFAP interrater and test-retest reliability are excellent $(>0.99)$, both correlate with other balance and functional measures, and the mEFAP is sensitive to change over time.

Established populations for the epidemiologic studies of the elderly (EPESE) short physical performance battery $(S P P B)$. The SPPB is a short battery of the ability 
to maintain stance (e.g., tandem stance), the time to walk eight feet at usual gait speed, and the time to rise from a chair five times. The SPPB predicts selfreported disability, nursing home admission, and mortality [18, 19]. However, a subsequent study reported that usual gait speed alone predicted ADL and mobility-related disability almost as well as the full SPPB battery [21]. In a primary clinic sample, however, while usual gait speed predicted outcomes such as hospitalization and functional decline, the full EPESE battery provided additional predictive value, particularly in a VA cohort [67]. A related battery (the MOBLI index) includes 3-meter walk time, time to rise from a chair five times, and peak expiratory flow rate, three factors that predicted changes in selfreported inability or difficulty in walking a medium (e.g., quarter mile) distance [32]. The MOBLI battery also predicts mortality [47] and was better than gait speed alone in predicting walking difficulty [31].

Functional ambulation classification. The functional ambulation classification (FAC) [26] uses a five-point scale to rate the extent of human assistance (stand-by, intermittent touch, and continuous support) required to walk on varying surfaces (level, nonlevel, stairs, and inclines) while using an assistive device if necessary $[26,27]$ in patients with neurological impairment. While no reliability data are reported, the FAC does correlate with temporal-distance measures such as step length and velocity.

Functional obstacle course. In the FOC, the subject must traverse a series of 12 simulations of functional mobility tasks or situations commonly encountered in and around the home environment [42, 43]. The subject walks approximately $100 \mathrm{~m}$ across flooring of different textures, as well as up and down ramps and stairs and over and around small obstacles. Outcomes include the time taken to complete the course as well as the quality of performance, i.e., the degree to which assistance and observed difficulty or unsteadiness was observed. Based on videotape ratings of subject performance, interrater and intrarater reliability was excellent for both time and quality scores (correlations, presumably Pearson's $r,>0.98$ ) and test-retest coefficient of variation for completion time was $5 \%$ $[42,43]$. Fallers have poorer time and quality scores than nonfallers and the scores correlate with factors such as neurological impairment [43] as well as POMA score (performance-oriented mobility assessment, see below) [45]. Practice on the FOC, as a part of an exercise program, did not help reduce falls [44]. In another version of a FOC [57], subjects walk in tandem, on foam, up and down a ramp and stairs, after picking up a box, under blinds suspended from the ceiling, and over a styrofoam block. Interrater reliability for video-rating quality scores (e.g., need for adaptive behaviors, steadiness, etc.) was high (Kappa $>0.95)$ and while test-retest quality scores were highly correlated (ICC $>0.9)$, there were small improvements in mean scores $(11 \%)$. Similar reliability and changes were noted with completion time. Both quality score and time correlated with measures such as the POMA and gait speed, and both quality score and time improved as a result of an exercise program, particularly in those with poorer scores initially. Note that one of the interesting issues not well addressed in these studies is the concept of timeaccuracy trade-off, in that faster performance may occur at the expense of errors or poorer quality score. It appears that all subjects were instructed to walk at a comfortable pace, and were generally not instructed regarding the quality score, although there was probably an implicit assumption that the goal was safe performance without the use of assistance.

Gait abnormality rating scale. The gait abnormality rating scale (GARS) utilizes a videotaped four level assessment of 16 individual gait descriptors with a focus on the lower extremity, trunk, and upper extremity [82]. Items in the scale that best distinguish a group of nursing home fallers from nonfallers include limitation in shoulder extension, arm-heel-strike asynchrony, and guarded stepping and arm swing. Interrater reliability (Spearman $r$ ) for total score was $>0.95$ but per item ranged from 0.5 to 0.9 [82]. The modified GARS (GARS-M), a seven-item version, includes the items noted above plus variability in stepping and arm movements, staggering (partial losses of balance), the degree to which the heel-strike occurs before forefoot impact, and loss of hip extension during gait [75]. This seven-item version was analyzed in frail ambulatory veterans and had moderate interrater and intrarater reliability (Kappa 0.6 for individual items, ICC $>0.9$ for total score, when done by trained physical therapists), good test-retest reliability (ICC $>0.9$ ), and correlated with gait speed and a history of falling. Using a cut-off score of 9 in this same cohort resulted in a modest sensitivity of $62 \%$ and specificity of $87 \%$ in predicting two or more falls in the past year [74], compared to 72 and $74 \%$, respectively, for comfortable gait speed of $0.6 \mathrm{~m} / \mathrm{s}$. Thus, these changes in gait may be more predictive of falls than simple gait speed.

Performance-oriented mobility assessment. The POMA, also known as the Tinetti balance and gait scale, is one of the earliest and most widely used batteries designed to assess balance, gait, and fall risk in older adults. The POMA includes an evaluation of balance under perturbed conditions (such as while 
rising from a chair, after a nudge, with eyes closed, and while turning) as well as an evaluation of gait characteristics (including gait initiation, step height, length, continuity and symmetry, trunk sway, and path deviation) [69]. Lower scores on the POMA have been associated with increased falls [70] and with increased cerebral white matter disease, possibly related to cerebrovascular disease [78]. A recent study of frail older adults showed that scores on the B-POMA (balance section of the POMA) were significantly different between fallers and nonfallers, with a score of 11 or less being predictive of a history of recurrent falls (odds ratio 18.5 ; sensitivity $83 \%$; specificity $72 \%$ ) [68]. A score less than 19 out of 28 has a sensitivity of $68 \%$ and a specificity of $88 \%$ for predicting an individual who will have two or more falls [71]. A later amended version suggests that a score of 36 out of 40 identified single fallers with $70 \%$ sensitivity and $52 \%$ specificity [53]. Initial reports suggest more than $90 \%$ interrater agreement on individual items [69]. Note that a ceiling effect might be noted in the POMA, even in moderately disabled Parkinson's patients, while gait speed will continue to differentiate subtle changes in functional ability [5]. This ceiling effect may have accounted for the sharp drop in sensitivity on a ROC curve to detect fall risk or it may also be a sign that other factors significant in fall causation (e.g., vision or environmental hazards) are not captured by the test [53].

Timed up and go test (TUG). The TUG is a measure of the time taken to stand up from a chair with armrests, walk $3 \mathrm{~m}$, turn, walk back to the chair, and sit down. Difficulty and/or unsteadiness in TUG performance is recognized as an important part of fall risk assessment [2]. In small community functionally impaired samples, intraclass coefficients for short periods are good: ICC $>0.9$ for less than 1 week [52] and ICC $=0.74$ for 2 weeks [28]. Sensitivity and specificity for a history of falls is $\operatorname{good}(87 \%,[63])$. A cut off score of $14 \mathrm{~s}$ or greater has been proposed as $80 \%$ sensitive and $100 \%$ specific for a history of falls [63]. Reliability was found to be modest $(\mathrm{ICC}<0.6)$ in a large $(n=2,305)$ sample of which $63 \%$ were found to have cognitive impairment and $29 \%$ were unable to complete the test due to immobility, safety concerns, or refusal [54]. Note that a shorter version (a walking distance of $2.44 \mathrm{~m}$ or $8 \mathrm{feet}$ ) has also been proposed with similar predictive value for a history of falls; this same study also found a substantially lower cut-off score for TUG in those with a history of falls, i.e., $10 \mathrm{~s}$ [56]. Other studies suggest a cut-off of $12 \mathrm{~s}$ for community older adults $(77 \%$ were below $10 \mathrm{~s}$ ) [8], and $20 \mathrm{~s}$ for independence on most (but not all) ADLs [52]. With its simplicity in administration and scoring, the TUG is among the most widely used of the measures noted in this study.

\section{Dual-task walking}

Recently, dual-task performance has been linked to an increased risk of falls based on walking performance while performing a simultaneous cognitive (dual) task. The risk of falls, measured prospectively, increases in assisted living residents who stop walking while talking [39]. This simple "stops walking while talking" test, however, may be only useful in subjects who are very impaired in the ability to walk anyway [25]. Adding an additional task to be performed simultaneously with the TUG may, however, add clinical utility. LundinOlsson [40] compared TUG performance time either without or with a simultaneous upper extremity (carrying a full glass of water) task. Followed prospectively, those subjects with a difference of $4.5 \mathrm{~s}$ or greater between the two TUG tests had nearly a five times higher risk of falling. Note that the upper extremity task involves some attentional demand, and the outcome given, that no subjects spilled any water, reflects mastery of the dual task. Given that the task was to carry the glass during walking only and that the water level was $5 \mathrm{~cm}$ from the top of the glass, the motor and attentional demands were modest. ShumwayCook et al. [63] also compared TUG performance time either without or with a simultaneous cognitive (counting backwards by threes) or upper extremity (carrying a full glass of water) task. When comparing community-dwelling older adults either with or without a history of falls, both simultaneous cognitive and upper extremity tasks increased TUG time equally (over $20 \%$ ), but did not provide additional predictive value (i.e., sensitivity or specificity) for a history of falls. One of the main issues in dual-task studies is how the subject prioritizes walking vs the additional cognitive/ motor task; is the subject instructed to prioritize one over the other, or does the subject self-prioritize, thereby adding an additional element of variability? Another related issue is the level of performance of the dual task; does the subject maintain a certain level of performance on the dual task or does the dual-task performance decrease in the presence of the walking task? In general, in these studies, information regarding dual-task performance outcomes or prioritization are not given. In a community sample followed prospectively, Verghese [76] found that older adult fallers (vs nonfallers) took longer to walk 20 feet, turn, and return while reciting the letters of the alphabet 
(walking while talking-simple, WWT-S) or alternate letters of the alphabet (walking while talking-complex, WWT-C). Interrater reliability, given only for the WWT-S, was fair for a timed task of a single trial $(r=0.6)$. Both WWT tests had good specificity (89$96 \%$ ) but only modest sensitivity (39-46\%). No score was given for either cognitive task, but the authors note that a number of subjects who slowed down also made errors in the alternate letter task. Had the subjects been forced to perform the alternate letter task without errors, walking might have slowed even more, suggesting that there may have been an underestimation of the effect of divided attention. In one prospective study in 85-year olds [10], fallers had slower walk time and poorer performance on verbal fluency, and, without prioritization of either task, poorer walk time and verbal fluency performance in a dual task situation. In contrast to previous studies of a dual-task effect, no disproportionate dual-task effect and no difference in the percent of those who stopped walking while "talking" was seen in fallers vs nonfallers, suggesting no benefit from using a dual task to predict falls. Thus, the dual task effect did not differ between different levels of fallers and nonfallers. This finding may have more to do with the fall classification scheme, in that 1 year recollection and surrogate reports were used and may not be reliable, although the faller group was more functionally impaired (such as in depressive symptoms). Another possibility has to do with the complexity of the tasks (walking plus three 180 deg turns), which was likely to be difficult in all three groups, and because of this complexity, the relatively preserved verbal fluency had little differential group dual task effect.

\section{Tests of volitional stepping}

In reacting to a postural disturbance, a foot-in-place response is frequently not sufficient, necessitating a compensatory stepping response. Laboratory-based protocols designed to induce compensatory stepping (using, for example a waist pull) frequently show that older and more balance-impaired individuals, compared to young controls, take more steps and have biomechanically less effective response strategies [36, 59]. These compensatory steps may differ from volitional steps, the latter triggered by a verbal or sensory (light or sound) commands. Compared to compensatory steps, volitional steps are executed more slowly, and thus may underestimate the true compensatory stepping ability [38]. Volitional stepping studies have found age- and impairment-associated declines in reaction time (the time of foot activation), but also describe declines in step completion time, the time taken to complete a step. Simple step completion time is generally slowest in older adult fallers (vs healthy old and young controls) when stepping laterally onto instrumented pads in response to a simple light stimulus [77]. Choice step completion time (stepping laterally or forward onto a switch with either foot in response to a light cue) is also prolonged in fallers vs nonfallers, correlates strongly with other immobility and fall risk factors (such as Trails B score and leg strength), and is an independent predictor for falls [34]. While there may be prolongation of step completion time with increasing age, there may be no disproportionate increase in simple vs choice step completion time [37]. One problem with stepping tests is that subjects may not have to substantially transfer their weight to complete a "step", thereby making the outcome a partial step, transferring just enough weight to activate the switch. This may occur because the step distance to switch activation is not individualized, i.e., to account for differences according to leg length and severity of the balance impairment. To encourage weight transfer and to provide a more individualized assessment of stepping ability, Medell and Alexander [46] instructed subjects to step out as far as possible and still successfully return to the original stance position in one step, the maximal step length (MSL). MSL declines with age and balance impairment and correlates strongly with measures of balance, fall risk, mobility performance, and self-reported function in balance-impaired older adults $[12,46]$. Allowing more than one step in returning to stance (an altered version of the MSL) showed greater decline from the third to the ninth decade of life than other gait and balance measures [33]. Test-retest reliability of the MSL is high ( $\mathrm{ICC}=0.86$ ) and while the MSL was originally tested in three directions with either foot, a simplified version more appropriate for clinical settings (right foot forward only) is equally predictive of the functional outcomes above [12]. Tests requiring steps in multiple directions with different feet have also been proposed. In the rapid step test (RST, [46]), subjects are timed as they take 24 steps in three directions with either foot in response to verbal commands. The time required to step into contiguous squares in a sequence of forward, sideways, and backward steps, each step needing to clear a low-lying obstacle (a set of canes), is called the four square step test (FSST, [13]. Both the RST and FSST are prolonged in balance-impaired or frequent-falling older adults, correlate with other measures of mobility, balance, and fall risk measures, and are reliable (test-retest ICC $>0.9$ ) [13, 46]. The 
step test is the number of times that a person can place the foot up onto and then down off a 5 -cm block repeatedly in $15 \mathrm{~s}$ without hand support [60]. The testretest reliability of this test in older people after hip fracture is excellent (ICCs of 0.92 and 0.85 for the affected and unaffected legs, respectively) [60]. Studies are needed to confirm its validity as a measure of balance-impairment and falls risk in older adults. The Berg balance scale (BBS) is a valid and reliable tool used in the assessment of balance in older adults $[6,7]$. It is a 14-item scale that assesses ability to perform a series of balance and mobility-related tasks such as going from sit to stand, standing with eyes closed, retrieving an object from the floor, and other tasks. One of the more challenging items appears to be a stepping task (placing alternate feet on a stool for a total of eight steps while standing unsupported) that requires shifting the center of gravity and changing to a narrow base of support [11]. A recent study of balance-related tests in older adults, indicated that the stepping task of the BBS was able to discriminate single fallers from multiple fallers (odds ratio $=46$, $p=0.005$ ) [11].

\section{Summary}

There are a number of advantages of simple gait assessment measures: they do not require expensive equipment and facilities; relative ease of and minimal time needed for administration; potential for acceptance by older adults who might fear technology-based assessments; and potential to simulate more typical challenges incurred during day to day living. High-tech assessment measures utilize highly quantifiable measures that assess more subtle phenomena and underlying pathological mechanisms not readily detectable by the clinician. These high-tech measures are also utilized during highly controlled laboratory protocols that may not fully reflect complex real-world situations. Frequently, a set of multiple tasks is proposed because gait disorders have multifactorial etiologies and may manifest themselves differently under different postural (or environmental) challenge situations. These sets of multiple tasks may provide additional sensitivity for changes in performance beyond the simpler performance or questionnaire tests. The simple sets may be most useful in more impaired individuals because of ceiling effects in the more able participants. Sometimes the sets may require additional equipment or space, such as in the obstacle courses that defeat the purpose of the simplicity of the measure and make the test more complex and less portable. Which measure is thus best to use? Selection of the proper instrument will depend on level of participant ambulation impairment (e.g., community ambulator vs home-bound) and the need for simple (e.g., busy clinic or hospital setting) vs more timeconsuming but informative multiple-task assessments (e.g., rehabilitation setting).

\section{References}

1. Alexander NB (1996) Gait disorders in older adults. J Am Geriatr Soc 44:434-451

2. American Geriatrics Society (2001) Guideline for prevention of falls in older persons. J Am Geriatr Soc 49:664-672

3. Baer HR, Wolf SL (2001) Modified Emory Functional Ambulation Profile: an outcome measure for the rehabilitation of poststroke gait dysfunction. Stroke 32:973-979

4. Bean JF, Kiely DK, Leveille SG, Herman S, Huynh C, Fielding R, Frontera W (2002) The 6-minute walk test in mobility-limited elders: what is being measured? J Gerontol A Biol Sci Med Sci 57:M751-M756

5. Behrman AL, Light KE, Miller GM (2002) Sensitivity of the Tinetti Gait Assessment for detecting change in individuals with Parkinson's disease. Clin Rehabil 16:199-405

6. Berg K, Wood-Dauphinee S, Williams JI, Gayton D (1989) Measuring balance in the elderly: preliminary development of an instrument. Physiother Can 41:304-311

7. Berg KO, Maki BE, Williams JI, Holliday PJ, WoodDauphinee SL (1992) Clinical and laboratory measures of postural balance in an elderly population. Arch Phys Med Rehabil 73:1073-1080

8. Bischoff HA, Stahelin HB, Monsch AU, Iversen MD, Weyh A, von Dechend M, Akos R, Conzelmann M, Dick W, Theiler R (2003) Identifying a cut-off point for normal mobility: a comparison of the timed 'up and go' test in community-dwelling and institutionalized elderly women. Age Ageing 32:315-320

9. Bittner V, Weiner DH, Yusuf S, Rogers WJ, McIntyre KM, Bangdiwala SI, Kronenberg MW, Kostis JB, Kohn RM, Guillotte $M$ et al (1993) Prediction of mortality and morbidity with a six-minute walk test in patients with left ventricular dysfunction. JAMA 270:1702-1707

10. Bootsma-van der Wiel A, Gussekloo J, de Craen AJM, van Exel E, Bloem BR, Westendorp RG (2003) Walking and talking as predictors of falls in the general population: the Leiden 85-plus study. J Am Geriatr Soc 51:1466-1471

11. Chiu AY, Au-Yeung SS, Lo SK (2003) A comparison of four functional tests in discriminating fallers from non-fallers in older people. Disabil Rehabil 25:45-50

12. Cho B, Scarpace D, Alexander NB (2004) Maximum step length: an indicator of mobility and dynamic balance in atrisk older adults. J Am Geriatr Soc 52:1168-1173

13. Dite W, Temple VA (2002) A clinical test of stepping and change of direction to identify multiple falling older adults. Arch Phys Med Rehabil 83:1566-1571

14. Ettinger WH, Burns R, Messier SP, Applegate W, Rejeski WJ, Morgan T, Shumaker S, Berry MJ, O'Toole M, Monu J, Craven T (1997) A randomized trial comparing aerobic exercise and resistance exercise with a health education program in older adults with knee osteoarthritis. JAMA 277:25-31 
15. Faggiano P, D’Aloia A, Gualeni A, Lavatelli A, Giordano A (1997) Assessment of oxygen uptake during the 6-minute walking test in patients with heart failure: preliminary experience with a portable device. Am Heart J 134:203-206

16. Fransen M, Crosbie J, Edmonds J (1997) Reliability of gait measurements in people with osteoarthritis of the knee. Phys Ther 77:944-953

17. Green J, Forster A, Young J (2002) Reliability of gait speed measured by a timed walking test in patients one year after stroke. Clin Rehabil 16:306-314

18. Guralnik J, Ferrucci L, Simonsick EM, Salive ME, Wallace RB (1995) Lower extremity function in persons over the age of 70 years as a predictor of subsequent disability. N Engl J Med 332:556-561

19. Guralnik J, Simonsick EM, Ferrucci L, Glynn RJ, Berkman LF, Blazer DG, Scherr PA, Wallace RB (1994) A short physical performance battery assessing lower extremity function: association with self-reported disability and prediction of mortality and nursing home admission. J Gerontol 49:M85-M94

20. Guralnik JM, Ferrucci L, Balfour JL, Volpato S, Di Iorio A (2001) Progressive versus catastrophic loss of the ability to walk: implications for the prevention of mobility loss. J Am Geriatr Soc 49:1463-1470

21. Guralnik JM, Ferrucci L, Pieper CF, Leveille SG, Markides KS, Ostir GV, Studenski S, Berkman LF, Wallace RB (2000) Lower extremity function and subsequent disability consistency across studies, predictive models, and value of gait speed alone compared with the Short Physical Performance Battery. J Gerontol A Biol Sci Med Sci 55A:M221-M231

22. Guyatt GH, Thompson PJ, Berman LB, Sullivan MJ, Townsend M, Jones NL, Pugsley SO (1985) How should we measure function in patients with chronic heart and lung disease. J Chronic Dis 38:517-524

23. Hamilton DM, Haennel RG (2000) Validity and reliability of the 6-minute walk test in a cardiac rehabilitation population. J Cardiopulm Rehabil 20:156-164

24. Harada ND, Chiu V, Stewart AL (1999) Mobility-related function in older adults: assessment with a 6-minute walk test. Arch Phys Med Rehabil 80:837-841

25. Hausdorff JM, Balash Y, Giladi N (2003) Effects of cognitive challenge on gait variability in patients with Parkinson's disease. J Geriatr Psychiatry Neurol 16:53-58

26. Holden MK, Gill KM, Magliozzi MR, Nathan J, Piehl-Baker L (1984) Clinical gait assessment in the neurologically impaired: reliability and meaningfulness. Phys Ther 64:35-40

27. Holden MK, Gill KM, Magliozzi MR (1986) Gait assessment for neurologically impaired patients: standards for outcome assessment. Phys Ther 66:1530-1539

28. Jette AM, Jette DU, Ng J, Plotkin DJ, Bach MA (1999) Are performance-based measures sufficiently reliable for use in multicenter trials. J Gerontol A Biol Sci Med Sci 54:M3-M6

29. Kervio G, Carre F, Ville NS (2003) Reliability and intensity of the six-minute walk test in healthy elderly subjects. Med Sci Sports Exerc 35:169-174

30. King B, Judge JO, Whipple R, Wolfson L (2000) Reliability and responsiveness of two physical performance measures examined in the context of a functional training intervention. Phys Ther 80:8-16

31. Lan TY, Deeg DJH, Guralnik JM (2003) Responsiveness of the index of mobility limitation: comparison with gait speed along in the Longitudinal Aging Study Amsterdam. J Gerontol A Biol Sci Med Sci 58:721-727

32. Lan TY, Melzer D, Tom BD, Guralnik JM (2002) Performance tests and disability: developing an objective index of mobility-related limitations in older persons. J Gerontol 57:M294-M301

33. Lindemann U, Bauerle C, Muche R et al (2003) Age-related differences in balance, strength, and motor function. Eur J Geriatr 5:15-22

34. Lord SR, Fitzpatrick RC (2001) Choice stepping reaction time: a composite measure of falls risk in older people. J Gerontol A Biol Sci Med Sci 56A:M627-M632

35. Lord SR, Menz H (2002) Physiologic, psychologic, and health predictors of 6-minute walk performance in older people. Arch Phys Med Rehabil 83:907-911

36. Luchies CW, Alexander NB, Schultz AB, Ashton-Miller JA (1994) Stepping responses of young and old adults to postural disturbances: kinematics. J Am Geriatr Soc 42:506-512

37. Luchies CW, Schiffman J, Richards LG, Thompson MR, Bazuin D, DeYoung AJ (2002) Effects of age, step direction, and reaction condition on the ability to step quickly. $J$ Gerontol A Biol Sci Med Sci 57A:M246-M249

38. Luchies CW, Wallace D, Pazdur R, Young S, DeYoung AJ (1999) Effects of age on balance assessment using voluntary and involuntary step tasks. J Gerontol A Biol Sci Med Sci 54A:M140-M144

39. Lundin-Olsson L, Nyberg L, Gustafson Y (1997) Stops talking while walking as a predictor of falls in elderly people. Lancet 349:617

40. Lundin-Olsson L, Nyberg L, Gustafson Y (1998) Attention, frailty, and falls: the effect of a manual task on basic mobility. J Am Geriatr Soc 46:758-761

41. Marquis S, Moore MM, Howieson DB, Sexton G, Payami H, Kaye JA, Camicioli R (2002) Independent predictors of cognitive decline in healthy elderly persons. Arch Neurol 59:601-606

42. Means KM (1996) The obstacle course: a tool for the assessment of functional balance and mobility in the elderly. J Rehabil Res Dev 33:413-428

43. Means KM, Rodell DE, O'Sullivan PS (1996) Use of an obstacle course to assess balance and mobility in the elderly. Am J Phys Med Rehabil 75:88-95

44. Means KM, Rodell DE, O'Sullivan PS, Cranford LA (1996) Rehabilitation of elderly fallers: pilot study of a low to moderate intensity exercise program. Arch Phys Med Rehabil 77:1030-1036

45. Means KM, Rodell DE, O'Sullivan PS, Winger RM (1998) Comparison of a functional obstacle course with an index of clinical gait and balance and postural sway. J Gerontol A Biol Sci Med Sci 53A:M331-M335

46. Medell JL, Alexander NB (2000) A clinical measure of maximal and rapid stepping in older women. J Gerontol A Biol Sci Med Sci 55A:M429-M433

47. Melzer D, Lan TY, Guralnik JM (2003) The predictive validity for mortality of the index of mobility-related limitation-results from the EPESE study. Age Ageing 32:619-625

48. Montgomery PS, Gardner AW (1998) The clinical utility of a six-minute walk test in peripheral arterial occlusive disease patients. J Am Geriatr Soc 46:706-711

49. Newman AB, Haggerty CL, Kritchevsky SB, Nevitt MC, Simonsick EM (2003) Walking performance and cardiovascular response: associations with age and morbidity-the health, aging, and body composition study. J Gerontol A Biol Sci Med Sci 58A:715-720

50. Ostchega Y, Harris TB, Hirsch R, Parsons VL, Kington R, Katzoff M (2000) Reliability and prevalence of physical performance examination assessing mobility and balance in older persons in the US: data from the Third National 
Health and Nutrition Examination Survey. J Am Geriatr Soc 48:1136-1141

51. Parent E, Moffet H (2002) Comparative responsiveness of locomotor tests and questionnaires used to follow early recovery after total knee arthroplasty. Arch Phys Med Rehabil 83:70-80

52. Podsiadlo D, Richardson S (1991) The timed "Up \& Go": A test of basic functional mobility for frail elderly persons. J Am Geriatr Soc 39:142-148

53. Raiche M, Hebert R, Prince F, Corriveau H (2000) Screening older adults at risk of falling with the Tinetti balance scale. Lancet 356:1001-1002

54. Rockwood K, Awalt E, Carver D, MacKnight C (2000) Feasibility and measurement properties of the functional reach and timed up and go tests in the Canadian study of health and aging. J Gerontol A Biol Sci Med Sci 55A:M70 M73

55. Rolland YM, Cesari M, Miller ME, Penninx BW, Atkinson HH, Pahor M (2004) Reliability of the 400-m usual-pace walk test as an assessment of mobility limitation in older adults. J Am Geriatr Soc 52:972-976

56. Rose DJ, Jones CJ, Lucchese N (2002) Predicting the probability of falls in community-residing older adults using the 8-foot up-and-go: a new measure of functional mobility. J Aging Phys Act 10:466-475

57. Rubenstein LZ, Josephson KR, Trueblood PR, Yeung K, Harker JO, Robbins AS (1997) The reliability and validity of an obstacle course as a measure of gait and balance in older adults. Aging 9:127-135

58. Salbach NM, Mayo NE, Higgins J, Ahmed S, Finch LE, Richards CL (2001) Responsiveness and predictability of gait speed and other disability measures in acute stroke. Arch Phys Med Rehabil 82:1204-1212

59. Schulz BW, Ashton-Miller JA, Alexander NB (2005) Compensatory stepping in response to waist pulls in balanceimpaired and unimpaired women. Gait Posture 22:198-209

60. Sherrington C, Lord SR (2005) Reliability of simple portable tests of physical performance in older people after hip fracture. Clin Rehabil 19:496-504

61. Shinkai S, Watanabe S, Kumagai S, Fujiwara Y, Amano H, Yoshida H, Ishizaki T, Yukawa H, Suzuki T, Shibata H (2000) Walking speed as a good predictor for the onset of functional dependence in a Japanese rural community population. Age Ageing 29:441-446

62. Shumway-Cook A, Baldwin M, Polissar NL, Gruber W (1997) Predicting the probability for falls in communitydwelling older adults. Phys Ther 77:812-819

63. Shumway-Cook A, Brauer S, Woollacott M (2000) Predicting the probability for falls in community-dwelling older adults using the timed get up and go test. Phys Ther 80:896-903

64. Shumway-Cook A, Gruber W, Baldwin M, Liao S (1997) The effect of multidimentional exercises on balance, mobility and fall-risk in community-dwelling older adults. Phys Ther 77:46-57

65. Simonsick EM, Montgomery PS, Newman AB, Bauer DC, Harris T (2001) Measuring fitness in healthy older adults: the health ABC long distance corridor walk. J Am Geriatr Soc 49:1544-1548

66. Simonsick EM, Newman AB, Nevitt MC, Kritchevsky SB, Ferrucci L, Guralnik JM, Harris T (2001) Measuring higher level physical function in well-functioning older adults: expanding familiar approaches in the health ABC study. J Gerontol A Biol Sci Med Sci 56A:M644-M649
67. Studenski S, Perera S, Wallace D, Chandler JM, Duncan PW, Rooney E, Fox M, Guralnik JM (2003) Physical performance measures in the clinical setting. J Am Geriatr Soc 51:314-322

68. Thomas JI, Lane JV (2005) A pilot study to explore the predictive validity of 4 measures of falls risk in frail elderly patients. Arch Phys Med Rehabil 86:1636-1640

69. Tinetti ME (1986) Performance-oriented assessment of mobility problems in elderly persons. J Am Geriatr Soc 34:119-126

70. Tinetti ME, Speechley M, Ginter SF (1988) Risk factors for falls among elderly persons living in the community. $\mathrm{N}$ Engl J Med 319:1701-1707

71. Tinetti ME, Williams TF, Mayewski R (1986) Fall risk index for elderly patients based on number of chronic disabilities. Am J Med 80:429-434

72. Toro B, Nester CJ, Farren PC (2003) The status of gait assessment among physiotherapists in the United Kingdom. Arch Phys Med Rehabil 84:1878-1884

73. Urquhart DM, Morris ME, Iansek R (1999) Gait consistency over a 7-day interval in people with Parkinson's disease. Arch Phys Med Rehabil 80:696-701

74. VanSwearingen JM, Paschal KA, Bonino P, Chen TW (1998) Assessing recurrent fall risk of community-dwelling frail older veterans using specific tests of mobility and the physical performance test of function. J Gerontol A Biol Sci Med Sci 53A:M457-M464

75. VanSwearingen JM, Paschall KA, Bonino P, Yang JF (1996) The modified gait abnormality rating scale for recognizing the risk of recurrent falls in community-dwelling elderly adults. Phys Ther 76:994-1002

76. Verghese J, Buschke H, Viola L, Katz M, Hall C, Kuslansky G, Lipton R (2002) Validity of divided attention tasks in predicting falls in older individuals: a preliminary study. $\mathrm{J}$ Am Geriatr Soc 50:1572-1576

77. White KN, Gunter KB, Snow CM, Hayes WC (2002) The quick step: a new test for measuring reaction time and lateral stepping velocity. J Appl Biomech 18:271-277

78. Whitman GT, Tang T, Baloh RW (2001) A prospective study of cerebral white matter abnormalities in older people with gait dysfunction. Neurology 57:990-994

79. Whitney SL, Hudak MT, Marchetti GF (2000) The dynamic gait index relates to self-reported fall history in individuals with vestibular dysfunction. J Vestib Res 10:99-105

80. Whitney SL, Wrisley DM, Marchetti GF, Gee MA, Redfern MS, Furman JM (2005) Clinical measurement of sit-to-stand performance in people with balance disorders: validity of data for the five-times-sit-to-stand test. Phys Ther 85:1034-1045

81. Wolf SL, Catlin PA, Gage K, Gurucharri K, Robertson R, Stephen K (1999) Establishing the reliability and validity of measurements of walking time using the Emory Functional Ambulation Profile. Phys Ther 79:1122-1133

82. Wolfson L, Whipple R, Amerman P, Tobin JN ( 1990) Gait assessment in the elderly: a gait abnormality rating scale and its relation to falls. J Gerontol A Biol Sci Med Sci 45:M12M19

83. Wrisley DM, Marchetti GF, Kuharsky DK, Whitney SL (2004) Reliability, internal consistency, and validity of data obtained with the functional gait assessment. Phys Ther 84:906-918

84. Wrisley DM, Walker ML, Echternach JL, Strasnick B (2003) Reliability of the dynamic gait index in people with vestibular disorders. Arch Phys Med Rehabil 84:1528-1533 